\title{
Convivência e Manejo dos Resíduos Sólidos: Uma Análise da Gestão Ambiental em Campos Sales-CE
}

\author{
Maria de Nazaré Antão de Alencar ${ }^{1}$; Anny Kariny Feitosa ${ }^{2}$; Vanda Lúcia Roseno Batista ${ }^{3}$
}

\begin{abstract}
Resumo: O objetivo da presente pesquisa foi analisar a gestão dos resíduos sólidos na cidade de Campos SalesCE. Para tanto, realizou-se um de estudo de caso, no qual foram utilizados os instrumentos: análise documental, visitas ao lixão, entrevistas a catadores de resíduos e aplicação de questionários junto à população. Constatou-se que o município possui um Plano de Gerenciamento Integrado de Resíduos Sólidos Urbano, desde 2008, entretanto, a prática na gestão e gerenciamento dos resíduos não atende às exigências da Lei Federal $\mathrm{n}^{\circ}$ 12.305/10. A disposição final dos resíduos é realizada em um vazadouro a céu aberto; no lixão foram identificados catadores que sobrevivem da catação de recicláveis, atuando informalmente, sem receber apoio ou orientação por parte do setor público ou empresa especializada com relação ao uso dos equipamentos de proteção individual - EPI; a população desconhece a legislação vigente e não possui o hábito de segregar seus resíduos na fonte geradora.
\end{abstract}

Palavras-chave: Gestão de Resíduos; Resíduos Sólidos Urbanos; Políticas Públicas.

\section{Coexistence and Management of Solid Waste: An Analysis of Environmental Management in Campos Sales - CE}

\begin{abstract}
The aim of this research was to analyze the solid waste management in the city of Campos Sales - CE. Therefore, there was a case study in which instruments were used: document analysis, visits to the dump, interviews with waste pickers and questionnaires with the population. It was found that the city has an Integrated Management Plan for Urban Solid Waste since 2008, however, the practice in the management and management of waste does not meet the requirements of Federal Law $\mathrm{n}^{\circ} .12,305 / 10$. The final disposal of waste is carried out in a dump in the open; the dumpsite scavengers were identified who survive the recyclable grooming, acting informally, without receiving support or guidance from the public sector or specialized company regarding the use of personal protective equipment - PPE; the population is unaware of the current legislation and do not have the habit of segregating their waste at the source.
\end{abstract}

Keywords: Waste Management; Urban Solid Waste; Public Policy.

\section{Introdução}

Os Resíduos Sólidos são apontados como qualquer forma de matéria ou substância, no estado sólido e semissólido, que resulte da atividade industrial, domiciliar, hospitalar, comercial, agrícola, de serviços, de varrição e de outras atividades humanas, capazes de causar poluição ou contaminação ambiental (BRASIL, 2010).

\footnotetext{
${ }^{1}$ Especialista em Geografia e Meio Ambiente pela URCA. Docente na Secretaria de Educação do Estado do Ceará - SEDUC CE.

E-mail: mnazareaalencar@hotmail.com;

${ }^{2}$ Doutoranda em Ambiente e Desenvolvimento pela UNIVATES. Docente no Instituto Federal do Ceará - IFCE.

E-mail: akfeitosa@hotmail.com

${ }^{3}$ Doutora em Geografia pela UNESP. Docente na Secretaria de Educação do Estado do Ceará - SEDUC CE.

E-mail: vandatist@hotmail.com
} 
Até recentemente, a humanidade não tinha percebido que o volumoso lixo que produzia podia ser um problema para o ambiente. Então usava sem grandes preocupações áreas vazias, inclusive mares e rios, como depósito para seus rejeitos (SCARLATO, 2009, p.08).

Desde 2010, o Brasil possui diretrizes legais para a gestão dos resíduos sólidos, implementadas pela Política Nacional de Resíduos Sólidos (PNRS), instituída pela Lei nº 12.305/2010, que estabelece prazos para que o país se ajuste, no que se refere à estrutura necessária à destinação adequada dos resíduos sólidos e também dos rejeitos.

A PNRS determina que a gestão integrada de resíduos sólidos é um conjunto de ações voltadas para a busca de soluções de forma a considerar as dimensões política, econômica, ambiental, cultural e social, com controle social e sob a premissa do desenvolvimento sustentável. Já o gerenciamento de resíduos sólidos são ações exercidas, direta ou indiretamente, nas etapas de coleta, transporte, transbordo, tratamento e destinação final ambientalmente adequada dos resíduos sólidos e disposição final ambientalmente adequada dos rejeitos em aterros sanitários.

Em seu Art. $14^{\circ}$, a Lei $n^{\circ} 12.305 / 2010$ apresenta as orientações acerca dos planos a serem elaborados a nível nacional, estadual, microrregional, intermunicipal e o plano municipal de gestão integrada de resíduos sólidos. Nesses planos devem ser estabelecidos diagnósticos, diretrizes, metas e prazos. Uma das metas dos Planos Estaduais de Resíduos Sólidos é a eliminação e recuperação de lixões, associada à inclusão social e à emancipação econômica de catadores de materiais reutilizáveis e recicláveis.

Frente a exigência e urgência dos municípios projetarem caminhos para a aplicabilidade da Lei, que sugere que se opte por soluções consorciadas intermunicipais para a gestão dos resíduos sólidos, incluída a elaboração e implementação de plano intermunicipal, ou se inserirem de forma voluntária nos planos microrregionais de resíduos sólidos referidos no $\S 1^{\circ}$ do Art. 16, inclusive na construção dos aterros sanitários.

De acordo com Batista (2015), o cenário da gestão dos resíduos sólidos no Brasil começou a mudar com a institucionalização da PNRS. Contudo, conforme dados disponibilizados pela ABRELPE - Associação Brasileira de Empresas de Limpeza Pública e Resíduos Especiais, prevalecem práticas inadequadas de gestão de resíduos em boa parte dos municípios brasileiros. Dentre eles, destacam-se os $46,49 \%$ dos municípios nordestinos, que mantêm a disposição dos resíduos em lixões a céu aberto (ABRELPE, 2014).

Diante do exposto, este artigo teve como objetivo analisar a gestão dos resíduos sólidos na cidade de Campos Sales-CE, bem como conhecer as políticas públicas existentes e compreender os impactos socioambientais da Política Nacional de Resíduos Sólidos e do Plano de Gerenciamento Integrado de Resíduos Sólidos Urbanos, como principais diretrizes de gerenciamento dos resíduos no município. 
Id on Line Revista Multidisciplinar e de Psicologia

Id on Line Multidisciplinary and Psychology Journal

\section{Materiais e Método}

O município de Campos Sales fica localizado no sudoeste do estado do Ceará, mais precisamente na Macrorregião Cariri, com uma extensão territorial de $1.082,769 \mathrm{~km}^{2}$. O seu bioma é a Caatinga, sua população é de 26.506 habitantes (IBGE, 2013). A área estudada pode ser visualizada por meio da Figura 1, apresentada a seguir.

Figura 1 - Localização do Município em relação ao Estado do Ceará

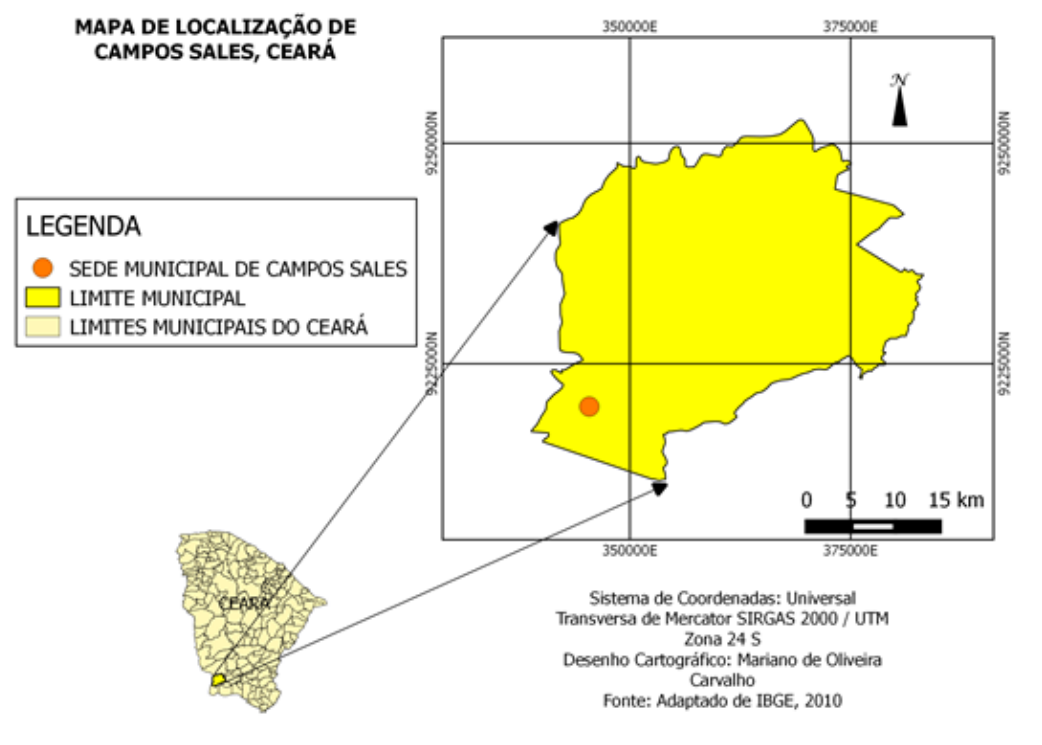

Fonte: Adaptado de IBGE (2013)

O presente artigo foi elaborado através da abordagem quanti-qualitativa e bibliográfica, com pesquisa de caráter exploratório-descritivo.

Segundo Gil (2002), a pesquisa exploratória tem por objetivo aproximar-se do tema, criando maior familiaridade em relação ao fato ou fenômeno. De acordo com Cervo et al. (2007), a pesquisa descritiva observa, registra, analisa e correlaciona fatos ou fenômenos variáveis, sem manipulá-los. Procura descobrir, com a maior precisão possível, a frequência com que um fenômeno ocorre, sua relação e conexão com outros, sua natureza e características. Busca conhecer as diversas situações e relações que ocorrem na vida social, política, econômica e demais aspectos, do comportamento humano, tanto do indivíduo tomado isoladamente como de grupos e comunidades mais complexas.

Para o desenvolvimento desta pesquisa, foram utilizados os seguintes instrumentos de investigação: aplicação de 30 (trinta) questionários junto à população residente de 4 (quatro) bairros no município de Campos Sales; entrevista à representante da Secretaria Municipal de Meio Ambiente; entrevistas aos catadores de resíduos que sobrevivem da catação no lixão; visitas ao lixão; análise de 
Id on Line Revista Multidisciplinar e de Psicologia

Id on Line Multidisciplinary and Psychology Journal

documentos existentes no município; registros fotográficos durante as visitas in loco; bem como realização de anotações durante visitas e observações nos bairros.

\section{Resultados e Discussão}

Os resultados desta pesquisa estão dispostos a seguir, divididos nos tópicos "Considerações sobre o PGIRS de Campos Sales" e "Diagnóstico do manejo dos Resíduos Sólidos Urbanos".

\section{Considerações gerais sobre o PGIRS de Campos Sales}

Desde 2002, o município de Campos Sales dispõe de um Plano Diretor de Desenvolvimento Urbano - PDDU, instituído e regulamentado pela Lei Municipal no 239/2002. Neste, já é presente uma preocupação com a destinação adequada dos resíduos sólidos, citando a coleta seletiva e a reciclagem como práticas desenvolvidas no município.

O Plano de Gerenciamento Integrado de Resíduos Sólidos Urbanos (PGIRSU) é o principal instrumento de gerenciamento dos resíduos na cidade de Campos Sales e foi construído em agosto de 2008, em atendimento à solicitação feita pela Superintendência Estadual do Meio Ambiente SEMACE, como complementação ao PPDU, encontra-se regulamentado na Lei $n^{\circ}$ 6.938/81, que instituiu a Política Nacional do Meio Ambiente, e na Lei $\mathrm{N}^{\circ}$ 13.103, de 24 de Janeiro de 2001 da Política Estadual de Resíduos Sólidos. A criação desta política representou um marco legal para todas as políticas públicas para o meio ambiente para todos os entes federados, pois anteriormente a ela os estados e municípios tinham autonomia para eleger as suas diretrizes políticas para o meio ambiente (PGIRSU, 2008).

Alguns serviços são contemplados no plano de gerenciamento, entre os quais estão: a coleta e transporte aos resíduos sólidos regulares (lixo domiciliar e comercial); coleta e transporte ao destino final de resíduos sólidos volumosos (classificados como entulhos e diversificados); coleta e transporte diferenciado de resíduos de serviço de saúde (classificados como hospitalar e ambulatorial); varrição manual de Ruas e Avenidas e capinação manual e mecanizada de vias pavimentadas.

Referente ao gerenciamento dos resíduos sólidos urbanos de Campos Sales:

[...] os serviços de coleta e transporte ao destino final de resíduos sólidos regulares consiste na remoção porta a porta dos resíduos oriundos dos domicílios ou residências, atividades de comércio em geral, pequenas indústrias, órgãos públicos, desde que não apresentem riscos a saúde e admitem destinação similar à dos resíduos urbanos (PGIRSU, 2008, p. 11). 
Entende-se, a partir da leitura desse instrumento de gerenciamento de resíduos, que a coleta seletiva não será adotada oficial e obrigatoriamente, mas de maneira indireta como uma segunda alternativa por meio da associação de catadores, e que a coleta regular permanecerá sendo o método oficial de coleta, pois como está citado no plano todas as vias habitadas, com produtividade e velocidade serão atendidas pela coleta regular.

Os motoristas e garis trajam uniformes munidos dos equipamentos de proteção individual, estabelecido pelas normas do Ministério do Trabalho pertencente a essa atividade. O recolhimento nos pontos deverá ser feito com frequência diária nos turnos diurno e noturno. Que poderá também ser realizada aos domingos num contingente de $10 \%$ do total (PGIRSU, 2008, p.15).

De acordo com o PGIRSU, os resíduos oriundos da construção civil deverão ser coletados, os catadores terão à sua disponibilidade um caminhão coletor do tipo caminhão carroceria de madeira, equipamentos e ferramentas compatíveis aos serviços demandados, posteriormente levados e depositados no aterro municipal.

Os resíduos gerados pelos serviços de saúde, ou seja, produzidos nos hospitais, postos de saúde, clínicas, laboratórios, farmácias, clínicas veterinárias, terão coleta exclusiva, para posterior incineração. Porém enquanto não houver a segregação (sépticos e não sépticos) pelos que produzem o lixo patogênico, estes serão recolhidos pela coleta regular.

Todo o resíduo destinado ao lixão deverá ser pesado, consequentemente será implantada uma infraestrutura,

Os resíduos coletados durante a coleta regular são encaminhados para o destino final do contratante, ou seja, para o lixão e após este plano com a criação do aterro será encaminhada parte para o aterro e outra parcela para a Associação de Catadores (PGIRSU, 2008, p. 13).

O PGIRSU assegura, ainda, que os catadores de recicláveis serão inseridos no mercado de trabalho formal, com condições de segurança diferenciada da catação no lixão, pois serão integrados na Associação dos Catadores e em um futuro Centro de Triagem.

As ações apontadas sobre gerenciamento de resíduos têm como encarregada a Prefeitura Municipal, representada pela Secretaria de Obras e Urbanismo, que é incumbida pelos procedimentos de varrição, coleta e destinação final dos resíduos sólidos coletados na cidade, juntamente à Secretaria de Desenvolvimento Rural e Urbanismo.

São mencionados como parte das ações do PGIRSU alguns projetos de educação ambiental, entre eles: viveiro de mudas, construção da agenda 21, arborização do bairro Poço, Sinalização da via de acesso ao Parque Ecológico Boqueirão, Implantação da Agenda A3P nas Secretarias Municipais e instituições públicas, pesquisa científica da flora e fauna do parque ecológico. Contudo, a principal 
Id on Line Revista Multidisciplinar e de Psicologia

Id on Line Multidisciplinary and Psychology Journal

premissa do PGIRSU é a extinção do lixão e construção de um aterro sanitário, além de associar a coleta seletiva à Associação de Catadores por meio de adesão por parte da população e instituições. Já que os resíduos destinados de maneira inadequada trazem prejuízos à saúde das pessoas, independente de trabalharem com ele, pois a liberação de gazes na atmosfera, contaminação das águas superficiais e subterrâneas e do solo atingem insatisfatoriamente às comunidades.

Dentre as principais iniciativas, foi realizada a implantação da A3P (Agenda Ambiental na Administração Pública) nos órgãos públicos e nas empresas Branco do Brasil e Banco do Nordeste, em que materiais são doados e coletados para a Associação dos Catadores de Campos Sales-CE.

No alusivo plano é citado que a previsão do censo do IBGE de 2000, a produção média diária de resíduos sólidos regulares (lixo domiciliar e comercial) produzidos na área urbana de Campos Sales, de acordo com a projeção de resíduos para o ano de 2006 está estimada em 10.5 toneladas/dia (per capita $-0,90 \mathrm{~kg} / \mathrm{hab}$. dia, para uma população de 27.254 habitantes).

Conforme Gonçalves (2003), a produção de lixo é inevitável e inexorável. Todos os processos geram resíduos, desde o mais elementar processo metabólico de uma célula até o mais complexo processo de produção industrial. Por outro lado, a lata de lixo não é um desintegrador mágico de matéria. A humanidade vive em ciclos de desenvolvimento e neste momento estamos vivendo um ápice de desperdício e irresponsabilidade na extração dos recursos naturais esgotáveis.

Começar a entender as relações existentes entre as escolhas de consumo da população e de postura diante de situações simples do cotidiano é potencializar as possibilidades de minimizar os problemas que estão diretamente associados ao lixo.

\section{Diagnóstico do manejo dos Resíduos Sólidos Urbanos em Campos Sales}

A coleta dos resíduos sólidos na cidade de Campos Sales, CE, é realizada diariamente no centro da cidade, e de 2 a 4 dias por semana nos bairros. Os resíduos sólidos urbanos gerados no município são dispostos em um terreno público (FIGURA 2) de 6 hectares, pertencente à Prefeitura Municipal, situado a $7 \mathrm{Km}$ da sede municipal. 
Figura 2 - Lixão na cidade de Campos Sales

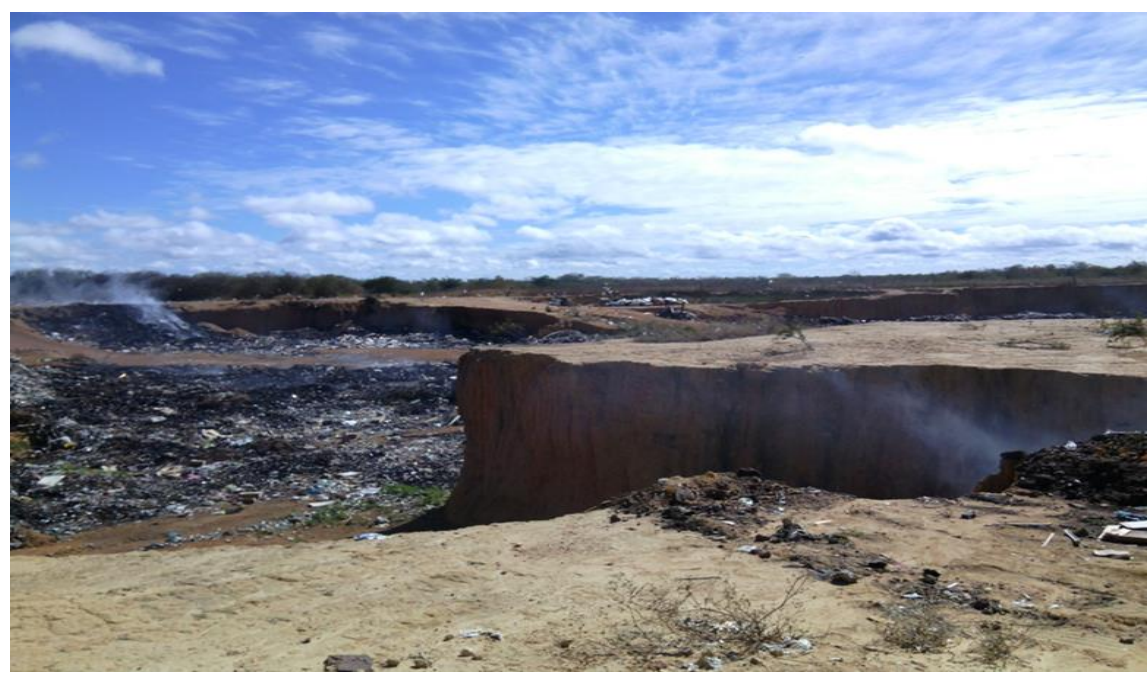

Fonte: Pesquisa aplicada.

O processo de degradação do terreno onde fica o lixão acontece desde o ano 2000. Conforme PGIRSU,

(...) esta área é utilizada para a disposição dos resíduos sólidos urbanos durante os últimos oito anos aproximadamente e, atualmente continua degradando e impactando o solo, a água e o ar, o que evidentemente necessita urgentemente de uma alternativa de solução para este grave quadro de degradação ambiental (PGIRSU, 2008, p. 08).

Nas proximidades do lixão existem pequenas propriedades e frequentemente os moradores queixam-se de mau cheiro e vetores de doenças atraídos pela decomposição dos resíduos a céu aberto. As doenças relacionadas ao mau gerenciamento dos resíduos são um dos desafios a serem enfrentados pela humanidade. Pois atraem ratos e pulgas que por meio da mordida, urina, fezes e picada transmitem leptospirose, peste bubônica e tifo murinho; mosca por meio do contato com a asa, pata, corpo, fezes e saliva transmite febre tifoide, cólera, amebíase, disenteria, giardíase e ascaridíase; mosquito através da picada transmite malária, febre amarela e dengue (PGIRSU, 2008). Registra-se, ainda, a imensa probabilidade de contaminação e erosão do solo, principalmente no período chuvoso, poluição do ar pela liberação de gases do efeito estufa durante o processo de decomposição.

Até a presente data, consta que $90 \%$ dos domicílios são atendidos pela coleta de resíduos, que é realizada na sede e nos distritos Quixariú, Itaguá, Barão de Aquiraz, Carmelópoles, Monte Castelo, Poço de Pedra e Caldeirão.

Em conformidade com o PGIRSU o método adotado para o serviço de coleta dos resíduos gerados é a deposição em sacos plásticos, descartados em vias públicas nos depósitos de metal disponíveis, que diariamente são recolhidos manualmente para o veículo coletor por funcionários 
contratados pela prefeitura, em itinerários e horários preestabelecidos. Os coletores são orientados a apanhar os sacos com cuidado para evitar o rompimento e espalhamento de restos nas vias públicas. Quando ocorre a queda durante a coleta são varridos e recolhidos.

No lixão municipal, observou-se a presença de 14 catadores, incluindo homens, mulheres e crianças, os quais sobrevivem dos restos depositados no lixão, apresentando um quadro de degradação socioambiental digno de receber interferência do poder público. Alguns passam dias no local e outros, ao final de cada dia, retornam para suas residências ou de algum familiar que reside na cidade ou no distrito mais próximo, denominado Caldeirão. Anteriormente à elaboração do PGIRSU, já havia a Associação de Catadores de Material Reciclável de Campos Sales, com sede fornecida pela Prefeitura. Com a descontinuidade das políticas municipais, a associação encontra-se inativa, fato que representa um retrocesso na gestão dos resíduos no município.

Utilizou-se uma amostra de $40 \%$ dos catadores que trabalham no lixão para serem entrevistados e, segundo seus relatos e a visualização do pesquisador, todos trabalham sem os equipamentos de proteção individual (EPI’s) e convivem com a fumaça diária. As equipes que trazem os resíduos nos caminhões colocam fogo e por isso a fumaça é permanente no local.

Os trabalhadores de materiais recicláveis cozinham em um barraco quase demolido e repousam em ambiente insalubre, dentro do lixão. Nos depoimentos, afirmaram trabalhar de maneira individual, mas existe uma ajuda mútua. A parceria entre os catadores é uma estratégia para enfrentamento das dificuldades apresentadas rotineiramente, entre elas, o aluguel de caminhões para transportar materiais até os atravessadores residentes nas cidades de Araripina - PE e Tauá - CE.

O trabalho dos catadores, durante a separação dos resíduos, é diário. Há prioridade para alguns tipos de resíduos por ser maior a facilidade para comercialização, já que o acesso a mercados diversos é inexistente. Neste sentido, corroboram Feitosa et al. (2015, p. 5), baseando-se nos resultados de uma pesquisa realizada no município de Iguatu - CE, em que verificaram "a necessidade do fortalecimento da organização dos catadores, via a formação de uma cooperativa, possibilitando avanço, por meio de melhores condições de trabalho, vida, renda, valorização do produto e mercado". Na Figura 3, podemos visualizar uma parcela dos materiais separados pelos catadores no lixão de Campos Sales. 
Figura 3 - Materiais recicláveis separados pelos catadores

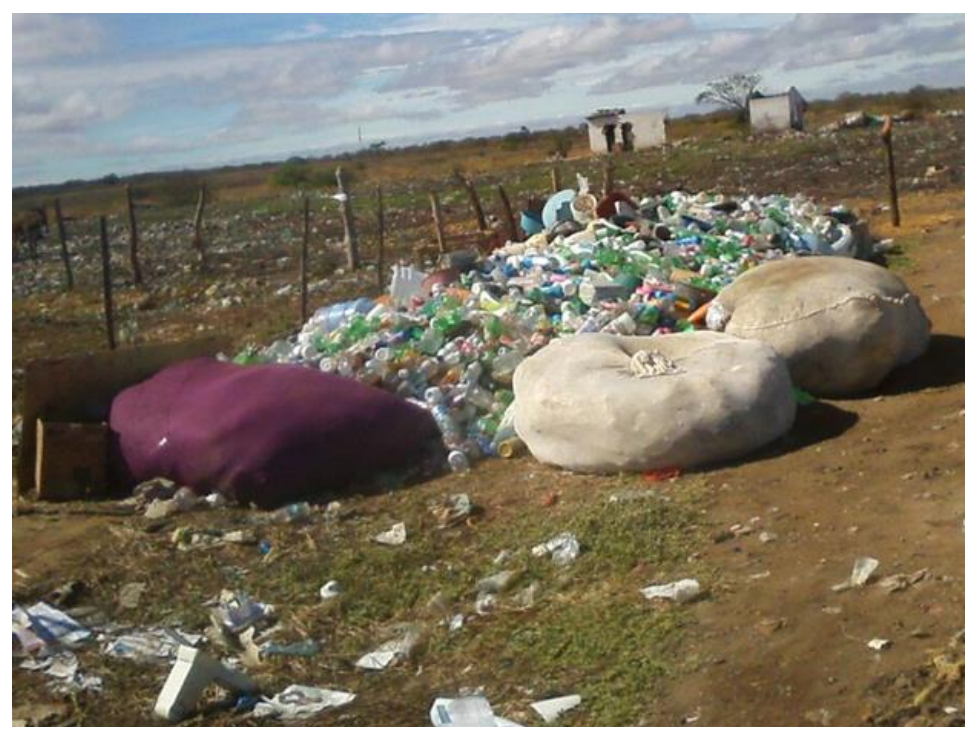

Fonte: Pesquisa aplicada.

Os catadores, durante as entrevistas, mencionaram não existir incentivo e apoio do poder público municipal. O trabalho é independente e só permanecem no lixão por falta de opção, pois, além da falta de acesso à condições de higiene e infraestrutura, sofrem com a constante desvalorização dos materiais, diante da oscilação dos preços por não terem alcance a mercados diversificados. Isto pois, de acordo com o IPEA, na comercialização de materiais recicláveis há incidência de uma maior sazonalidade no desempenho das atividades, que ocorre conforme variações nos preços dos materiais recicláveis, na oferta de resíduos (IPEA, 2011 apud IPEA, 2013).

Durante uma entrevista realizada junto à Secretária de Desenvolvimento Rural e Meio Ambiente do município de Campos Sales - CE, foi declarada a ação de implantação da coleta seletiva de papel nas instituições públicas, que posteriormente seria expandida para os demais resíduos.

A Secretária mencionou haver reuniões referentes à futura implantação consorciada do aterro sanitário, com previsão de ser instalado no município de Assaré - CE. Afirmou, ainda, a existência do Plano de Gestão Integrada de Resíduos Sólidos, nos padrões exigidos pelas exigências da Lei $n^{\circ}$ 12.305/2010. Entretanto, mencionou como principal dificuldade para implantação efetiva da PNRS a falta de apoio financeiro dos governos federal e estadual para esse fim.

Segundo a Lei no 12.305/2010, no Art. 18 é dito que,

A elaboração de plano municipal de gestão integrada de resíduos sólidos, nos termos previstos por esta lei, é condição para o Distrito Federal e os municípios terem acesso a recursos da União, ou por ela controlados, destinados a empreendimentos e serviços relacionados à limpeza urbana e ao manejo de resíduos sólidos, ou para 
serem beneficiados por incentivos ou financiamentos de entidades federais de crédito ou fomento para tal finalidade (BRASIL, 2010).

Para os municípios com população inferior a vinte mil habitantes o plano tem modelo simplificado, para os municípios com população superior é fundamental seguir o conteúdo mínimo na Lei $n^{\circ}$ 12.305/2010, no Art. 19, entre os quais são apresentados alguns,

\begin{abstract}
Um diagnóstico da situação dos resíduos sólidos com identificação de áreas favoráveis para disposição final ambientalmente adequada de rejeitos; procedimentos operacionais e especificações mínimas a serem adotados nos serviços públicos de limpeza urbana e de manejo de resíduos sólidos; regras para o transporte e outras etapas do gerenciamento de resíduos sólidos; programas e ações de capacitação técnica voltadas para sua implementação e operacionalização; programas e ações de educação ambiental que promovam a não geração, a redução, a reutilização e a reciclagem de resíduos sólidos; programas e ações para a participação dos grupos interessados, em especial das cooperativas ou outras formas de associação de catadores de materiais reutilizáveis e recicláveis formadas por pessoas físicas de baixa renda; mecanismos para a criação de fontes de negócios, emprego e renda. (BRASIL, 2010)
\end{abstract}

Em 09 de dezembro de 2014, foi aprovado o Decreto $n^{\circ} 425$ prorrogando o prazo para a disposição final ambientalmente adequada dos rejeitos de que trata o art. 54 da Lei 12.305/2010, que institui a PNRS. A justificativa mencionada neste decreto foi que expirado o prazo a grande maioria dos municípios não conseguiu cumprir a determinação legal, alegando falta de quadros técnicos e deficiência e recursos insuficientes (BRASIL, 2014).

Segundo dados divulgados pela ABRELPE (2014), o Brasil tem evoluído no que se refere à destinação adequada dos resíduos sólidos, mas ainda encontra-se distante das metas almejadas, com $28,2 \%$ de vazadouros a céu aberto e 31,86\% de aterros controlados. Como relata Gonçalves (2003),

\footnotetext{
Obedecendo não só o aspecto sanitarista, mas também o ambiental, econômico e, principalmente, o social, o gerenciamento de resíduos deve envolver sempre e de forma institucionalizada os catadores de materiais reaproveitáveis. Afinal, eles compõem, historicamente, um grupo de trabalhadores que a sociedade finge que não vê, enquanto eles fingem que não existem (...). Ficamos alheios no processo, sem nos preocupar com o destino dos materiais reaproveitáveis que insistimos em jogar fora (...). O professor Sabetai Caderoni diz tudo já no título de seu livro Os bilhões perdidos no lixo. E todos nós sabemos que sai mais em conta, em termos energéticos, produzir a matéria-prima reciclável do que com a matéria prima virgem (GONÇALVES, 2003, p. 93).
}

Complementarmente, durante o desenvolvimento da pesquisa, foram aplicados 30 questionários junto à população campossalense, para conhecer sua percepção sobre a gestão e gerenciamento dos resíduos sólidos no município. Os resultados estão dispostos na Tabela 1. 
Id on Line Revista Multidisciplinar e de Psicologia

Id on Line Multidisciplinary and Psychology Journal

Tabela 1 - Percepção da população sobre gestão e gerenciamento de resíduos

\begin{tabular}{lcc}
\hline \multicolumn{1}{c}{ Pontos abordados } & Sim & Não \\
\hline Separação de resíduos & $90 \%$ & $10 \%$ \\
\hline Uso de resíduos orgânicos para fins de alimentação e/ou adubo & $73 \% \quad 27 \%$ \\
\hline Conhecimento da destinação final dos resíduos & $73 \% \quad 27 \%$ \\
\hline $\begin{array}{l}\text { Conhecimento da legislação referente à gestão de resíduos sólidos (Federal, Estadual } \\
\text { e/ou Municipal) }\end{array}$ & $20 \% \quad 80 \%$ \\
\hline Sabem da existência da Política Nacional de Resíduos Sólidos? & $6,7 \% \quad 93,3 \%$ \\
\hline Conhecimento de catadores de resíduos sólidos & $33 \% \quad 67 \%$ \\
\hline Conhecimento da existência de catadores que trabalham no lixão & $16 \% \quad 84 \%$ \\
\hline
\end{tabular}

Fonte: Pesquisa aplicada.

Conforme observa-se na Tabela 1, 80\% da população admitem possuir pouco conhecimento a respeito da legislação vigente referente à gestão de resíduos sólidos urbanos, seja em âmbito municipal, estadual ou federal. Este resultado está em consonância com os encontrados em uma pesquisa realizada em Lavras, Minas Gerais, em que Bicalho et al. (2016) demostraram que a população possuía pouco conhecimento sobre aspectos da gestão dos resíduos sólidos urbanos, como por exemplo: coleta seletiva, processos de elaboração e avaliação de políticas públicas, Conselho Municipal de Meio Ambiente, consumo consciente e importância dos catadores de materiais recicláveis.

Contudo, destaca-se positivamente nesta pesquisa que $90 \%$ dos populares mantêm o hábito de segregar os resíduos gerados na fonte, o que facilitaria inicialmente a implementação de uma campanha de coleta seletiva. Além disso, $73 \%$ da população promove o reaproveitamento dos resíduos orgânicos, seja para alimentação de animais doméstico ou ainda para a produção de adubo.

\section{Conclusões}

Verificou-se no espaço estudado a inexistência da aplicabilidade do PGIRSU, que apesar de não atender aos critérios da Lei $n^{\circ} 12.305 / 2010$, caso as ações propostas tivessem sido implementadas, hoje ter-se-ia uma iniciativa valorosa relacionada aos resíduos sólidos na cidade de Campos Sales, divergindo do cenário atual.

A disposição final dos resíduos é realizada em um vazadouro a céu aberto; no lixão foram identificados catadores que sobrevivem da catação de recicláveis, atuando informalmente, sem receber apoio ou orientação por parte do setor público ou empresa especializada com relação ao uso dos 
equipamentos de proteção individual - EPI. A população sofre as consequências associadas a essa problemática e pouco conhece sobre as questões envolvendo esse tema.

Assim, é urgente a necessidade de implementação de programas de educação ambiental no cotidiano. Adicionalmente, propõe-se que sejam implementadas alternativas para o reaproveitamento dos resíduos, como por exemplo a reciclagem de resíduos secos e a compostagem de resíduos orgânicos. Estas iniciativas poderiam trazer benefícios socioeconômicos para o município, além de melhorar suas condições sanitárias e qualidade de vida dos moradores, diminuindo a proliferação de portadores e transmissores de doenças provenientes do acúmulo de resíduos.

\section{Referências}

ABRELPE - Associação Brasileira de Empresas de Limpeza Pública e Resíduos Especiais. Panorama dos Resíduos Sólidos no Brasil - 2014. ABRELPE: São Paulo, 2015. Disponível em: <http://www.abrelpe.org.br/Panorama/panorama2014.pdf> Acesso em 10 de fev. de 2016.

BATISTA, Vanda Lúcia Roseno. A coleta seletiva como instrumento propulsor da gestão do consórcio de resíduos sólidos na região metropolitana do Cariri - Ceará. Tese (Doutorado em Geografia) - Universidade Estadual Paulista, Instituto de Geociências e Ciências Exatas, Rio Claro, 2015.

BICALHO, M. L.; PEREIRA, J. R.; ALCANTARA, S. S. Gestão dos Resíduos Sólidos e a educação ambiental: um estudo de caso de Lavras/MG. Revista Ibero-Americana de Ciências Ambientais, v. 7, n.1, 2016. Disponível em: <http://sustenere.co/journals/index.php/rica/article/view/SPC21796858.2016.001.0007> Acesso em 07 jun. 2016.

BRASIL. Lei $\mathbf{n}^{\mathbf{1}}$ 12.305, de 2 de agosto de 2010. Disponível em <: http://www2.camara.leg.br/documentos-e pesquisa/publicacoes/edicoes/paginas-individuais-doslivros/politica-nacional-de-residuos-solidos.> Acesso em: 31 ago. 2015.

BRASIL. Decreto $\mathbf{n}^{\mathbf{0}} \mathbf{4 2 5}$, de 09 de dezembro de 2014 . Disponível em: <http://www25.senado.leg.br/web/atividade/materias/-/materia/119536>. Acesso em: 02 abr. 2016.

FEITOSA, A. K.; LANDIM, G. H. P.; SILVA, K. B.; SILVA, G. D. A Educação Cooperativista na Formação de Catadores de Resíduos Sólidos em Iguatu, Ceará. Revista Verde (Pombal - PB - Brasil), v. 10, n.3, p $09 \quad$ - 13, jul-set, 2015. Disponível em: <http://www.gvaa.com.br/revista/index.php/RVADS/article/view/3639> Acesso em: 08 jun. 2016.

GIL, A. C., 1996. Como elaborar projeto de pesquisa. 4. ed. São Paulo: Atlas, 2002.

GONÇALVES, Pólita. A Reciclagem Integradora dos Aspectos Ambientais, Sociais e Econômicos. Rio de Janeiro: DP\&A, 2003.

IBGE. Departamento das Cidades. Disponível <http://cidades.ibge.gov.br/xtras/perfil.php?codmun=230270>. Acesso em: 12 mar. 2016. IPEA. Situação Social das Catadoras e dos Catadores de Material Reciclável e Reutilizável Brasil. IPEA, 2013. 
Id on Line Revista Multidisciplinar e de Psicologia

Id on Line Multidisciplinary and Psychology Journal

PGIRSU - Plano de Gerenciamento Integrado de Resíduos Sólidos. Prefeitura Municipal de Campos Sales. Fortaleza, 2008.

SCARLATO, Francisco C. Do nicho ao lixo: ambiente, sociedade e educação. $18^{a}$ ed. São Paulo: Atual, 2009.

\section{Como citar este artigo (Formato ABNT):}

ALENCAR, M.N.A.; FEITOSA, A.K.; BATISTA, V.L.R. Convivência e Manejo dos Resíduos Sólidos: Uma Análise da Gestão Ambiental em campos Sales - CE. Id on Line Revista Multidisciplinar e de Psicologia, Julho de 2016, vol.,10 n.30, Supl 1. p. 256-268. ISSN 1981-1179.

Recebido: $10 / 05 / 2016$

Aceito: $18 / 05 / 2016$ 